\title{
Los derechos humanos para las personas LGBT y sus limitantes frente al modelo de la ciudadanía normativa
}

Recibido: 22 de octubre 2018 Revisado: 9 de febrero 2019 Aprobado: 26 de abril 2019

Ericka López Sánchez

Mexicana. Doctora en Estudios Sociales por la Universidad Autónoma Metropolitana. Profesorainvestigadora de tiempo completo en el

Departamento de Estudios Políticos y de Gobierno de la Universidad de Guanajuato,

México, y miembro del Sistema Nacional de Investigadores.

Actualmente, desarrolla una investigación sobre "La condición ciudadana de las personas LGBT a partir de las narrativas de las políticas públicas en tres escenarios subnacionales: Ciudad de México,

Guanajuato y Tijuana". Asimismo, es cocoordinadora del proyecto “Diagnóstico de la participación política de la diversidad sexual en México", financiado por el Consejo Nacional de Ciencia y Tecnología. Un proyecto de

la Universidad Nacional Autónoma de México (UNAM) y la Universidad de Guanajuato. Correo electrónico:

e_08renacimiento@hotmail. com
Resumen: Los derechos humanos se implementan en el marco de los Estados democráticos, como un dispositivo potente que fortalece la calidad de las democracias, se posicionan como un discurso de verdad que resuelve las deficiencias de los Estados-nación. No obstante, a estos últimos, se eximen muchas veces de sus responsabilidades cotidianas; así como de una autoreflexión sobre el modelo normativo de ciudadanía generado por la democracia liberal que propicia, por su propia lógica, exclusiones que a su vez subsanan los derechos humanos, por lo que se cae en una tramposa legitimación de las democracias. El Estado, aunque democrático, tiene sexo y eso le hace generar cierto tipo de exclusiones relacionadas con la población LGBT; por consiguiente, el objetivo de este trabajo es analizar los caminos que se han tomado en la construcción de los derechos humanos para las personas LGBT, dentro de los contextos democráticos, y si estos son los más idóneos para romper con el orden heteronormativo, patriarcal y binario que apuntala la discriminación hacia estas poblaciones en el día a día, así como discutir las respectivas limitantes.

Palabras clave: Derechos humanos; personas LGBT; ciudadanía liberal; ciudadanías íntimas; derechos sociosexuados

\section{Human rights for LGBT people and their limitations against the model of normative citizenship}

Abstract: Human rights are implemented within the framework of democratic states, as a powerful device that strengthens the quality of democracies, they position themselves as a truth discourse that resolves the deficiencies of nation-states. However, to the latter, this often exempts them from their daily responsibilities; as well as a self-reflection on the normative model of citizenship generated by liberal democracy that, by its own logic, favors exclusions that in turn correct human rights, thus falling into a tricky legitimization of democracies. The State, although democratic, has sex and this causes it to generate certain types of exclusions, so the objective of this work is to analyze the paths that have been taken in the construction of human rights for LGBT people, within the democratic contexts, and if these are the most suitable to break with the heteronormative, patriarchal and binary order that underpins the discrimination towards these populations on a day-today basis, as well as discuss the limitations they have.

Key words: Human rights; LGBT people; liberal citizenship; intimate citizenships; sexual socialization rights 
1. El presente trabajo es un ensayo que reflexiona, analiza y discute sobre la tensión que se genera entre la construcción de los derechos humanos de las personas LGBT, en tanto ordenamiento supranacional y el modelo operativo de ciudadanía de la democracia liberal en el ámbito cotidianonacional, en la protección de los derechos ciudadanos de las personas no heteronormadas. Así pues, se revisó literatura crítica de la democracia liberal, específicamente los trabajos de las feministas politólogas y los ordenamientos de derechos humanos elaborados por las instancias internacionales que trabajan en pro de estas temáticas.

\section{Introducción ${ }^{1}$}

En algunas ocasiones, los derechos humanos arriban para solventar aspectos que las democracias liberales han marginado, discriminado y violentado dado la construcción del orden cívico-público: los sujetos son abstraídos de su materialidad corpórea para poder existir en el espacio público desde el principio imperante de la racionalidad para alcanzar la imparcialidad, la cual garantizará la convivencia desde una razón moral despojada de pasiones.

La construcción de los derechos humanos soluciona, principalmente, las problemáticas de grupos históricamente discriminados por su impronta racial, sexual, de género, religiosa y demás aspectos que atraviesan lo corporal y las identidades específicas. Así, se han instaurado como un discurso despojado de ideología con una validez supranacional que plantea recomendaciones a los países que se circunscriben a estos derechos.

El prestigio de verdad que han alcanzado los derechos humanos los ha colocado como parámetros para medir la calidad de las democracias. Se constituye, de este modo, una paradoja: la propia lógica del modelo normativo de ciudadanía de la democracia liberal lleva a la exclusión de todas aquellas personas que no alcanzan los estándares de igualdad requeridos. Pero dichas exclusiones les causan conflictos que les colocan en un estado de desprestigio dentro de un orden global que valora altamente los derechos humanos. Entonces, las democracias recurren a la suscripción de estos derechos para asegurar su lugar en el mundo a partir de su alto grado de calidad democrática.

De este modo, los derechos humanos, en tanto ordenamientos de carácter supranacional, han resuelto lo que las democracias no son capaces de solventar ya sea por desinterés, incapacidad, arbitrariedad o porque la lógica con la que funcionan no les alcanza para aprehender todos los conflictos.

La normatividad de los derechos humanos se ha instituido como una norma que opera de forma extraordinaria en los Estados-nación que los reconocen. No es una legalidad cotidiana, a la cual recurra de forma inmediata la ciudadanía, su acceso exige una lógica de conocimiento, precisa de conocimientos puntuales y tiempo; en este sentido, resulta importante reflexionar sobre: ¿cuáles son los alcances y limitaciones que tienen los derechos humanos para defender las discriminaciones y violencias cotidianas que vive la población LGBT?, ¿cuánto eximen el funcionamiento de los derechos humanos a los Estados, de legislar desde su propio marco normativo punitivo la defensa de esta población para que alcance una vida digna?, ¿en qué medida los derechos humanos que protegen a las personas LGBT aprehenden la complejidad de esta población desde una perspectiva de género que reconozca sus diferencias internas, que les lleva a presentar demandas distintas y no desde una concepción normativa? y ¿son elitistas los derechos humanos? Estas interrogantes son las que se pretenden responder en el presente trabajo. 


\section{La tensión ontológica entre el modelo de ciudadanía normativa y los derechos humanos}

Cuando hablamos de derechos humanos del LGBT, debemos preguntarnos qué ha llevado a la necesidad del diseño de un esquema de defensa de derechos humanos. Dicha interrogante nos remite al análisis del modelo imperante de la ciudadanía normativa que ha diseñado la democracia liberal y que rige el mundo moderno, de modo que reconsidera en el planteamiento de que las personas ciudadanas para estar en el espacio público deben abandonar sus cuerpos y especificidades, puesto que este paradigma político ignora todas las identidades y diferencias más locales, en aras de construir entes ciudadanos homogeneizados políticamente que respondan a los intereses de la democracia. "A despecho de su aparente universalidad y neutralidad, la noción vigente de ciudadanía está hecha a la medida de los ciudadanos varones" (Peña 2010, 232).

En este sentido, el avance de los derechos humanos del LGBT debe ir acompañado de la reflexión y el replanteamiento de la concepción de ciudadanía, que obstaculiza en la práctica la materialización de la idea de que los derechos humanos son inherentes a todos los seres humanos, sin distinción alguna en razón, lugar de residencia, sexo, origen nacional o étnico, color, religión, lengua, o cualquier otra condición, ya que en realidad prevalece una tensión ontológica entre la noción de ciudadanía y la de los derechos humanos: mientras la primera apela al desdibujamiento de los cuerpos para otorgar prerrogativas, la otra exige el reconocimiento de las especificidades corporales para eliminar la discriminación y las injusticias.

Los derechos civiles y políticos constitutivos de la ciudadanía son también parte fundamental de los derechos inalienables considerados por los derechos humanos, que se reconocen y se hacen valer en el espacio público. No obstante, lo civil y lo político no son ajenos a la constitución sexual; lo civil y lo político se han instaurado como dispositivos biopolíticos de control al servicio del modelo de la ciudadanía liberal:

El sexo, como órgano y práctica, no es ni un lugar biológico ni una pulsión natural. El sexo es una tecnología de dominación heterosocial que reduce al cuerpo a zonas erógenas en función de una distribución asimétrica del poder entre los géneros (femenino/masculino), haciendo coincidir ciertos afectos con determinados órganos, ciertas sensaciones con determinadas reacciones anatómicas. La naturaleza humana es un efecto de tecnología social que reproduce en los cuerpos, los espacios y los dis- 
cursos la ecuación naturaleza $=$ heterosexualidad $($ Preciado 2011, 17).

Como ya ha sido señalado por numerosas feministas, en función del orden heteronormativo patriarcal y binario se ha establecido la normatividad de la vida pública:

Los reclamos de status de ciudadanía, al menos en Occidente, están estrechamente asociados con la institucionalización del privilegio teterosexual y masculino (...) dentro de los discursos sobre los derechos de los/as ciudadanos/as y el principio de ciudadanía universal el ciudadano normal ha sido construido principalmente como masculino y heterosexual, aunque esto último ha sido mucho menos reconocido o discutido en la literatura (Richardson 200, 75).

En el espacio público debe imperar la razón normativa, aquella que solo se logra si se alcanza la imparcialidad y ésta a su vez sólo es posible de aprehender si se expulsa de la razón el deseo, la afectividad y el cuerpo. Las decisiones morales que se fundamentan en consideraciones de simpatía, preocupación y valoración de necesidades diferenciadas son definidas como no racionales, no objetivas, meramente sentimentales y que, por lo tanto, no tienen cabida en lo público.

Se establece, entonces, un orden público donde la razón se opone al deseo, a la afectividad y al cuerpo, con lo que lo cívico-público debe excluir los aspectos corporales y afectivos de la existencia humana; así se obliga a una homogeneidad de ciudadanía sobre lo cívico-público. Se excluye de dicho orden a aquellos sujetos y colectividades que no se adecuan al modelo de ciudadano racional que pueda trascender el cuerpo y los sentimientos (Young 1998, 455).

Desde este entendido del "deber ser" se instauran exclusiones, discriminaciones y violencias validadas en el espacio público:

Las leyes refuerzan prejuicios sociales existentes y permiten la violencia contra personas del LGBTI. Estas leyes han sido utilizadas para justificar detenciones arbitrarias, abuso policial, extorsión y tortura... Igualmente, la legislación destinada a proteger la "moral pública" es interpretada de manera que las personas del LGBTI pueden ser 
criminalizadas simplemente por expresar su identidad de género en un lugar público (Centro de Estudios Internacionales Gilberto Bosques 2016, 3).

Las disposiciones jurídicas implementadas por los Estados para violentar a los cuerpos no heteronormados no siempre son evidentes y explícitas. Por el contrario, en un marco internacional de exigencia al respeto a los derechos humanos, estas disposiciones se construyen de forma indirecta. Así la detención o la acusación se pueden basar aparentemente en razones distintas a la propia identidad o condición, aunque en realidad, estos argumentos son muchas veces un pretexto para accionar contra la orientación sexual o la identidad o expresión de género de una persona (Comisión Internacional de Juristas 2009, 79).

Paradójicamente, tales exclusiones y violencias han lacerado a las sociedades democráticas, puesto que lo distinto, lo alterno, lo no hegemónico existen y se posicionan en un orden supranacional donde los derechos humanos son cada vez más el lenguaje básico de las reivindicaciones de las organizaciones de la sociedad civil; es el discurso de verdad que se ha colocado como libre de ideologías y surge como un imperativo (Rabotniko 2005) insoslayable de atender. Hoy, los Estados del mundo occidental asumen la obligación y el deber, en virtud del derecho internacional, de respetar, proteger y realizar los derechos humanos de sus sociedades.

Mediante la ratificación de los tratados internacionales de derechos humanos, los Estados se comprometen a adoptar medidas y leyes internas compatibles con las obligaciones internacionales. Así, los Estados tienen el deber de prevenir las violaciones de los derechos humanos; en caso de no hacerlo, deben implementar todas las medidas y procedimientos necesarios con el fin de investigar lo sucedido, sancionar a los responsables y reparar a las víctimas (Naciones Unidas 2013). Esto porque se ha construido un vínculo entre democracia y derechos humanos para medir la calidad de las primeras:

A pesar de acoger postulados internacionales que pretenden homogeneizar la garantía de los derechos básicos de los individuos, atacan directa o soterradamente a los integrantes de estas minorías, ofensivas que muchas veces obedecen a la manipulación de las herramientas jurídicas a favor del sentir personal y el grado de tolerancia de sus dirigentes. La ausencia de reglamentaciones y decisiones judiciales e institucionales que velen por la defensa de los derechos de esta minoría resulta en detrimento, no sólo de su integridad como individuos políticos, sino también 
como sujetos inmersos en una colectividad. Es decir, que pretender desestimular las acciones excluyentes, discriminatorias y en muchos casos violentas en contra de este grupo por parte de diferentes actores sociales se convierte en un ideal difícil de alcanzar cuando los organismos estatales son los primeros en desconocer sus libertades y prerrogativas (Estefan Vargas 2013, 201).

En el caso mexicano, por ejemplo, en el resumen ejecutivo de la Investigación sobre Atención a Personas Lesbianas, Gays, Bisexuales y Trans en México, realizado en abril de 2016, se señala en sus conclusiones que el LGBT es un sector de la población que enfrenta un alto grado de vulnerabilidad, en las áreas de salud, educación, trabajo y derecho de las víctimas, se observan prácticas discriminatorias que impiden el pleno desarrollo en condiciones de seguridad. Sus posibilidades del libre goce de los beneficios sociales que otorga el Estado mexicano son obstaculizados, tanto por la población en su conjunto como por servidores y autoridades del servicio público.

Una de las principales formas de discriminación a la población LGBT es aquella ejercida por agentes del Estado, no sólo de manera directa a través de la labor desempeñada por miembros de las fuerzas militares o de policía, sino por medio de las disposiciones legales y judiciales (Estefan Vargas 2013, 186).

\section{La disyuntiva de los derechos humanos en el orden cotidiano}

En la vida cotidiana de las personas LGBT, los derechos humanos en favor de la orientación sexual y la identidad de género no impactan en su dignificación humana; en esta problemática de discriminación y violencia se traslapan dos cuestiones muy puntales: 1)los derechos humanos son un lenguaje jurídico internacional de recurrencia extraordinaria, no cotidiana, que exige para su apelación competencias de habla sofisticadas, por lo que no todos los sujetos de una sociedad están en condiciones de emplearlos y hacerlos valer, y 2)los derechos humanos no están cuestionando los modelos de ciudadanía normativa que sí rigen la vida cotidiana y que aspiran y apuntalan hacia lo homogéneo de los cuerpos para, en función de ello, otorgar derechos y visibilizar a ciertos tipos de ciudadanías para establecer parámetros de inclusión y exclusión, y delinear así los márgenes de lo aceptable y lo abyecto. Y aquí 
estriba la dificultad práctica de garantizar los derechos humanos de las personas LGBT.

Como ya se mencionó, los derechos humanos son un discurso de verdad internacional que, pese a ello, no son aún una práctica cotidiana de fácil acceso. En tanto discurso, se circunscriben a un tipo de lenguaje que posee reglas y requieren, por tanto, ser conocidas, poseer los conocimientos para usarlas y así poder ejercerse. Esto implica para los sujetos tener competencias de habla específicas que les permitan entrar en ese mundo simbólico y hacer un uso correcto de la gramática de los signos como se exige en ese contexto para desempeñarse con éxito. Los derechos humanos orientados a la defensa de las personas LGBT, por su propia naturaleza de orden supranacional, no son una regulación ordinaria, por lo general se apela a ellos cuando se ha cometido un acto discriminatorio que daña la dignidad de la persona. Pero como la demanda hacia ellos requiere un procedimiento puntual, riguroso, que exige conocimientos específicos y un lenguaje concreto, se recurre a los derechos humanos de forma escaza y no siempre con muy buenos resultados.

En las diversas conferencias, talleres y de espacios espacios académisos donde se ha tratado el tema de violencia contra las personas LGBT, dentro del contexto mexicano, ha sido recurrente los testimonios de las personas en manifestar que ante una discriminación o violencia por parte de una autoridad no acuden a las Procuradurías de Derechos Humanos, porque no suelen estar en la capital de sus estados y eso implica gastar tiempo y dinero, o bien desconocen el procedimiento por seguir.

Los Estados que han firmado acuerdos internacionales en la materia, legislan en su interior de forma suave, puesto que delegan su observancia a instancias administrativas, con lo que las sanciones guardan esos mismos matices.

Los derechos humanos dentro de los Estados se confrontan con el paradigma de ciudadanía normativa de la democracia liberal, justo con ese modelo que rige la vida cotidiana de los sujetos desde su sentido común. Las diferentes normatividades que rigen la vida social en las democracias están estructuradas para validar los cuerpos que se constriñen al orden heteropatriarcalbinario e invisibilizar los cuerpos que no se acotan a esta estructura. Todas las prerrogativas civiles y políticas se otorgan en función del ser hombre o mujer racional y en su única condición de heterosexual ${ }^{2}$. Esa es la exigencia suprema para habitar en el espacio público, en el sitio donde se asignan los derechos ciudadanos, ya que en el espacio privado se confinan las diferencias, los deseos, los sentimientos, las orientaciones sexuales, las identidades de género y todos aquellos aspectos de la vida que están asociados con el cuerpo.

El Tribunal Europeo de Derechos Humanos es el órgano de derechos humanos que más ha desarrollado la materia de orientación sexual e identidad de género en rela-

2. "Feministas (Iris Young), comunitarias (Michael Sandel) o partidarios de las políticas de identidad (Anna Galeotti) han elaborado críticas paralelas al neutralismo liberal: ¿por qué razón habrían de cancelarse las diferencias de los ciudadanos, como pretende el neutralismo?, ¿por qué habría que hacerlos aparecer "privados de identidad" si quieren acceder al papel central de la ciudadanía democrática (el

establecimiento de las reglas del juego)? Ciertamente, el neutralismo pretende que el objetivo de la cancelación de las diferencias es la igualdad de respeto y de trato. Pero también es verdad que ciertas diferencias, lejos de cancelarse, se mantienen siempre como condicionantes en la sombra (o como identidades 'invisibles' y dominantes: varón, blanco, heterosexual, de 40 a 60 años de edad, clase media alta, educado, etc.). Además, dado que el tema de la diferencia está conectado con privilegios y exclusiones, al impedir la aparición de ciertas diferencias en lo público, el punto de vista neutral tiende a reproducir el status quo. (Del Águila 2010, 372.) 
ción con el derecho a la vida privada. El Tribunal ha aprovechado varias oportunidades para reafirmar que 'no puede haber duda de que la orientación y la actividad sexual se refieren a un aspecto íntimo de la intimidad personal'...que el derecho al respeto de la 'vida privada' es el derecho a la intimidad, el derecho a vivir, en la medida en que uno lo desee, protegido de la publicidad...El Tribunal ha reafirmado que la propia esencia del convenio Europeo es el respeto de la dignidad y la libertad humanas, y que se protege el derecho de los transexuales al desarrollo personal y a la seguridad física y moral. En este campo, el Tribunal ha apuntado que el concepto de 'vida privada' es un término amplio que no es susceptible de una definición, y que cubre la integridad física y la integridad psicológica de una persona... (Comisión Internacional de Juristas 2009, 60).

En este entendido, la construcción de los derechos humanos no ha podido romper con esa concepción aspiracional de la homogeneidad de los cuerpos, que es el núcleo de la discriminación. Los derechos humanos hacen su tarea de vigilancia y sanción de la no discriminación desde la lógica misma de la ciudadanía normativa, llevando al campo de lo privado los grupos marcados por su impronta racial y sexual, que a su vez son identificados culturalmente con el cuerpo, lo salvaje, lo prohibido, lo patológico, lo pecaminoso, lo criminalizado y lo irracional, y que no le exigen a los Estados el reconocimiento de la intimidad desde lo político; se refuerza, con ello, el orden cívico-público. Asimismo, la cita anterior refuerza la idea de que la orientación sexual y la identidad de género deben quedar en lo privado, oculto de la vista y que no puede ser dado a conocer pues está conectado con la vergüenza. Se señala el respeto a la vida privada desde lo privado y no se discute el reconocimiento y el respeto de la intimidad en el espacio público. Así pues, pareciera no romperse la idea de reconocer ciertos derechos sexuales en la medida en que se ejerzan en el ámbito privado y se eludan las expresiones públicas de la sexualidad.

De este modo, la homosexualidad, el lesbianismo, la bisexualidad y lo trans deben quedar en el espacio privado: ahí donde nadie los ve, donde la razón no se daña, donde no se pone en jaque la homogeneidad heterosexual y la clara correspondencia "del sexo natural" con la "expresión de género correspondiente". 
La orientación sexual y la identidad de género se siguen pensando en la dicotomía espacio público versus espacio privado. Y el espacio es clave porque la sexualidad, en general, ha sido vista como perteneciente a la esfera privada y, por tanto, ha sido dejada por fuera del ámbito de la vida cívica y política. "La vida personal se organiza de tal manera que, en las democracias, las personas no normativas están excluidas de sus derechos plenos como ciudadanas" (Lind \& Argüello 2009, 14).

Ken Plummer hace referencia a la ciudadanía íntima y señala que esta se enfoca en "los derechos, obligaciones, reconocimiento y respeto en torno a las esferas más íntimas de la vida: con quién vivir, cómo educar a los hijos, cómo disponer del cuerpo, cómo relacionarse como un ser con género, cómo ser una persona erótica" (Plummer 2001).

Así, la práctica simbólica de "salir del closet", utilizada por las personas gays y lesbianas como una forma de empoderamiento, reflejan una metáfora de la división de lo público-privado. Dicha concepción de ciudadanía obliga a los Estados a reconocer a las personas en la vida pública en toda la extensión de sus especificidades corporales y aspectos confinados a lo privado. Tal postura rompe con el modelo hegemónico de la ciudadanía normativa.

En este replanteamiento de la noción de ciudadanía se ubica también la ciudadanía sexual, que es

aquella que enuncia, facilita, defiende y promueve el acceso de los ciudadanos al efectivo ejercicio de los derechos tanto sexuales como reproductivos y a una subjetividad política que no ha disminuido por las desigualdades basadas en características asociadas con sexo, género y capacidad reproductiva (Garrido Álvarez, Rafael José 2017, 15).

Esos modelos de ciudadanía que pueden ir aparejados implican no dejar ser quien se es ni en el espacio público ni en el privado:

La noción de ciudadanía sexual alude principalmente a tres áreas en las que los derechos de ciudadanía sexual -en tanto opuestos a la ciudadanía heterosexual social y políticamente dominante- deberían de ser reclamados: derechos a varias formas de prácticas sexuales; derechos relativos a la identidad propia y a las autodefiniciones y derechos en relación con instituciones sociales, ta- 
les como la validación pública de una vatiedad de relaciones sexuales (Richardson 2000, 99).

Respecto de tales replanteamientos de la noción de ciudadanía, Plummer (2003) propone un puente potencial entre lo personal y lo político, mediante su modelo de ciudadanía íntima. La propuesta estriba en que las diferencias que constituyen a los sujetos no queden abandonadas al ámbito de lo privado, sino que estas se reconozcan en lo público para construir desde ahí un nuevo orden de ciudadanía que sea capaz de dar cuenta de las relaciones personales, las emociones, el género la sexualidad, la identidad y los conflictos morales de la vida cotidiana. Lo anterior permitiría extender las responsabilidades y los derechos ciudadanos.

\section{Las limitaciones de los derechos humanos frente al modelo de ciudadanía normativa al momento de sancionar}

Por ello, es fundamental repensar la defensa de los derechos humanos desde la reestructuración del modelo de ciudadanía normativa; de lo contrario, las realidades seguirán dando cuenta de que los Estados no investigan exhaustiva e imparcialmente casos de abuso y de violencia. De acuerdo con el Centro de Estudios Internacionales Gilberto Bosques, en su informe sobre Los derechos de las personas LGBT en el mundo y la situación en México, en 2016, las estadísticas precisas sobre las condenas penales en casos de asesinatos y otros actos de violencia son limitadas o inexistentes en los Estados de América Latina. La información con la que se cuenta refleja altos niveles de impunidad para aquellos que cometen actos de violencia contra personas LGBT.

Se sabe que las personas LGBT y las minorías sexuales son más vulnerables a la violencia y a los abusos de los derechos humanos, incluidas las amenazas de muerte y las violaciones del derecho a la vida, y, con frecuencia, se cometen en un clima de impunidad. Es apropiado mencionar aquí una situación concreta: en el desarrollo de una terapia psicológica colectiva para personas trans y familiares, en la Ciudad de México, en mayo de 2017, un joven trans narró que constantemente él sufría golpizas y amenazas de muerte por parte de su hermano mayor a causa de su identidad de género.

Luego de un intento de asesinato, acudió al Ministerio Público a denunciarlo, aprehendieron a su hermano, lo metieron a declarar y posterior a esto, el agente del Ministerio Público mandó llamar al afectado y le dijo: "Esto no procede; tú nunca dijiste que no eras hombre". Amparado en "el discurso natural-biologicista-cisgénero", un funcionario público encargado de impartir justicia violentó la legalidad y el derecho humano del joven a recibir justicia. El joven de aproximadamente 19 años no supo más qué hacer; regresó a su casa esperando que el hermano, adicto a las drogas, en cualquier momento pueda 
volver a intentar algo en contra de su vida y con todo el aval de la madre que le reclama constantemente al joven trans ser un "monstruo".

Este es un ejemplo claro de las limitaciones de los derechos humanos en la vida cotidiana de las personas trans. Para este joven, acudir a la Comisión de los Derechos Humanos fue impensable, no así a la instancia legal legitimada por el derecho positivo en el que se sustentan las democracias. Pero no recibió justicia dada la legalidad heteronormativa que opera y la formación cultural del sujeto que aplica la norma.

\section{Los derechos humanos de las personas LGBT más que derechos sexuales}

Por lo general la mirada a la existencia de las personas LGBT se reducen a lo sexual; el sexo parece ser la piedra angular que constituye a las lesbianas, gays, bisexuales y personas trans, no así a los heterosexuales, a ellos se les piensa desde una constitución más amplia que trasciende lo sexual:

De acuerdo a la Organización Mundial de la Salud, los denominados derechos sexuales incluyen el derecho de toda persona libre de restricciones, discriminación y violencia; a lograr el más alto nivel de salud en relación con la sexualidad, incluyendo acceso a servicios de salud sexual y reproductiva; buscar, recibir e impartir información en relación con la sexualidad; educación sexual; respeto por la integridad del cuerpo; libertad para escoger pareja; decidir ser o no sexualmente activo/a; consentir las relaciones sexuales; consentir el matrimonio; decidir si quiere tener hijos o no y cuándo; buscar una vida sexual placentera, segura y satisfactoria (Naciones Unidas 2013, 4).

En función de esta reducción (que aparecen en todos los documentos de orientación sexual e identidad de género desde el enfoque de los derechos humanos), muchos de los derechos se construyen anclados en este orden de pensamiento: Los derechos sexuales y reproductivos, sin lugar a duda, son pieza clave en la dignificación de las personas y es una lucha que han ejercido por mucho tiempo las feministas para que las mujeres se constituyan como agentes sociales, dueñas de sus cuerpos, y que fueron fuertes batallas para que estos derechos aparecieran en las declaraciones de los derechos humanos; no obstante, esta acotación en la concepción de las personas 
LGBT, ya no puede quedarse más allí pues desdibuja nuevamente su estar en el espacio público como sujetos de derecho.

Por supuesto que hay una apelación clara y fuerte hacia la defensa del ejercicio de la sexualidad y la libre decisión del cuerpo, pero no lo es todo: las personas LGBT demandan derechos civiles, políticos y sociales que se les niegan o complican, justamente, por esa falta de reconocimiento de la orientación sexual e identidad de género diferente a la heteronormada y la cisnorma en la vida pública.

La Guía para profesionales número 4 de Orientación Sexual e Identidad de Género y Derecho Internacional de los Derechos Humanos realizada por la Comisión internacional de Juristas (2009) en Suiza, señala en su apartado siete, que la libertad de expresión, reunión pacífica y asociación aplicada a la orientación sexual y la identidad de género son cruciales para el activismo LGBT y la defensa de las personas que padecen VIH/SIDA.

Esta enunciación da cuenta de la forma en que se conciben a las personas no heteronormadas y no cisgénero desde la legalidad de los derechos humanos. Efectivamente, hay grupos LGBT activistas que es preciso que se les respete su libertad a expresarse y manifestarse libremente. Pero hay otras tantas personas LGBT, y quizás sean las más, que no son activistas y que tienen el derecho a participar en cualquier manifestación de la sociedad civil desde el reconocimiento de su orientación sexual o identidad de género no heteronormadas y trans.

Es decir, no se puede pensar en las personas LGBT solo a partir de una concepción gregaria, la garantía a su derecho a expresarse, reunirse y asociarse pacíficamente debe estar garantizado dentro o fuera del activismo; tampoco se puede hacer ese determinismo de que las personas LGBT demandan prioritariamente políticas públicas encaminadas a la prevención y solución del $\mathrm{VIH} / \mathrm{SIDA}$, ya que ese enunciado tiene como fondo una estigmatización; pareciera ser que esta pandemia de transmisión sexual que ha cobrado la muerte de miles de personas en el mundo es resultado de las prácticas sexuales no heterosexuales y solamente la padecen las personas LGBT.

Tal aseveración refuerza la estigmatización que se les hiciera en la década de los ochenta por la aparición y expansión del VIH/SIDA. Cabe señalar que, si bien es cierto fue una bandera de lucha prioritaria en los años noventa por las organizaciones y colectivos LGBT, dada las muertes que estaba causando la enfermedad y que eso las desvío de la lucha de derechos civiles y políticos -dando un lugar a un ambiguo proceso de ciudadanización y reconocimiento basado en supuestos de precariedad, victimización y vulnerabilidadque emprendieron a finales de los años setenta y que hoy sigue estando en sus líneas de acción, no es porque no sea una lucha ganada, sino porque es la única forma como los organismos internacionales -Banco Mundial (BM)- y los Estados-nación los reconocen como organizaciones de la sociedad civil para darles financiamiento y realicen programas de apoyo a la comunidad, pues hasta hoy es muy difícil que les asignen recursos para otras tareas que no sean las vinculadas con salud. 
Es preciso trascender la mirada patologizante y reduccionista en la construcción de los derechos humanos LGBT, que bloquea su dimensión de sujetos políticos y civiles en el espacio público desde el pleno reconocimiento de su orientación sexual e identidad de género, sin tener que negociar una performatividad heterosexual o pasar por una medicalización y cirugías para probar la autenticidad exitosa hacia la transición.

Los derechos humanos tendrían que estar más en consonancia con la extensión de derechos universales sobre el género y la sexualidad a toda la población, sin importar su orientación o identificación de género. Es el caso del matrimonio igualitario, la adopción, el derecho a una pensión en caso de defunción de la pareja, a cobrar el seguro de vida, lograr el cambio de identidad, así como armonización de las leyes para que el cambio de identidad sea de verdad un derecho consumado, etc.

Repensar los derechos humanos LGBT a partir de la diferenciación entre la orientación sexual y la identidad de género

Esta misma idea del determinismo sexual para mirar a los cuerpos disidentes ha llevado a agrupar a lesbianas, gays, bisexuales y personas trans dentro de una sola identidad y uniformar sus demandas dentro de una conceptualización homogeneizadora. Poco se repara en realizar un análisis con perspectiva de género y diferenciado dentro del LGBT y más aún hacer una distinción puntual entre el LGB y la T, pues el primer grupo reta el orden heteronormativo en relación con la orientación sexual y el segundo, la construcción binaria hombre-mujer "natural" desde la identidad de género.

En este sentido, las experiencias de discriminación y violencia se viven diferente porque estos cuerpos, aunque ponen en jaque el orden heteropatriarcal binario, lo hacen de forma distinta. Muchas personas lesbianas, gays y bisexuales negocian su condición de orientación sexual con el silencio o la perfomatividad heterosexual. Sin embargo, para las personas trans no puede ser pues ellas hacen una ruptura desde la corporalidad, y no solo desde la práctica -como las personas LGB-, de la "naturaleza coherente del sistema sexogénero", ponen en tensión lo cisgénero y lo trans, rompen con lo "aceptable de la estética binaria", establecen cuerpos femeninos con pene, cuerpos masculinos con vulva, que menstruan y con posibilidades de embarazarse.

La no diferenciación de la orientación sexual y la identidad de género implica subsumir la segunda en la primera, con lo que se construye una concepción hegemónica de lo cisgénero y desde esa hegemonía se dictan no únicamente los derechos legitimados por alcanzar, sino también se enuncian las discriminaciones que se van a reconocer como válidas. Con ello se establece, desde la formalidad, la idea de que se cumple con la atención a los derechos de las personas LGBT.

Reconocer a las personas LGBT en una sola identidad es delicado, por lo que es preciso acotar que las identidades son constructos sociales y, por lo 
tanto, no guardan esencias, sino relaciones con la otredad, dentro de un contexto social, político y cultural. Las identidades están conformadas por: atributos, estigmas y prejuicios que vuelven complejo el reconocimiento de las diferencias y construyen lo abyecto.

La Ilustración, como movimiento filósofico-epistemológico que implicó la ruptura con el orden tradicional, impuso la idea de la igualdad, que se tradujo en homogeneización y esto ha servido como un dispositivo de inclusión y exclusión: lo que no responde al estándar construido queda fuera de esa igualdad. Las diferencias, por ende, han tenido una concepción negativa, resultan antagónicas y amenazantes, y, además son más difíciles de controlar; en cambio, lo parecido facilita desarticular resistencias, atender demandas y vigilar.

Desde el enfoque de la identidad que los derechos humanos LGBT se han pensado y diseñado, por ejemplo, cuando se definen las obligaciones de los Estados con respecto a la protección de los derechos humanos de las personas LGBT, se señalan cinco de forma muy concreta:

1. Proteger a las personas contra la violencia homofóbica y transfóbica.

2. Prevenir la tortura, así como los tratos crueles, inhumanos y degradantes de las personas LGBTI privadas de libertad, prohibiendo y sancionando tales actos y garantizando que las víctimas reciban una reparación.

3. Derogar inmediatamente las leyes que penalizan la homosexualidad, incluyendo todas las leyes que prohíben las relaciones sexuales con consentimiento entre adultos del mismo sexo.

4. Prohibir la discriminación por motivos de orientación sexual e identidad de género.

5. Preservar la libertad de reunión, expresión y asociación pacífica para las personas LGBTI.

Estas cinco obligaciones hacen un tratamiento por igual de lesbianas, gays, bisexuales y personas trans; la lógica de agrupamiento se rige desde lo no heteronormado, todo lo que está en esta clasificación es igual. El Consejo para Prevenir y Eliminar la Discriminación de la Ciudad de México (COPRED) define así la población LGBT:

¿Quiénes pertenecen a la población LGBTTTI? La población LGBTTTI es la forma de referirnos al conjunto de personas que no se identifican con dicha heterosexualidad normalizada y que se han unido desde décadas atrás para luchar en favor de sus derechos, dado que tienen una serie de características comunes por encontrase en situación de discriminación, a pesar de que cada una de estas comunidades son diferentes entre sí (Consejo para 
Prevenir y Eliminar la Discriminación de la Ciudad de México 2017).

La centralidad contundente de este agrupamiento pasa por lo no heteronormado, por la ruptura con el orden sexo-genérico hegemónico y no hay un detenimiento para ahondar en las diferencias que se saben, porque se enuncian, pero que no se les da importancia.

Entre los hombres gays y las mujeres lesbianas las violencias y discriminaciones son diferentes; las mujeres lesbinas de entrada viven una doble discriminación por ser mujeres y ser lesbianas y sin considerar su condición de etnia, clase social, nivel académico, etc.

Lo mismo ocurre con las personas trans; hombres y mujeres trans viven de manera diferente las violencias y discriminaciones, pues el hecho de que los hombres trans puedan ser menos percibidos como tales en el espacio público los resguarda de violencias; no así para las mujeres trans, quienes son muy visibles.

Por otra parte, cuando se hace mención, en el punto dos de las obligaciones de los Estados con las personas LGBT, a la tortura o tratos crueles que pueden vivir las personas al ser privadas de su libertad por cometer un ilícito que amerite su aprehensión, no hay una definición clara del tipo de violaciones que puedan vivir las personas cisgénero y las personas trans, sin mencionar las intersexuadas, que es todavía más complejo. No se hace alusión a que las mujeres trans son las más afectadas en este aspecto, pues se les lleva a las cárceles de hombres y ahí son violadas sexualmente por los hombres detenidos y poco se sabe lo que ocurre con los hombres trans y tampoco es un tema atendido.

De la misma forma ocurre cuando se establece que los Estados garanticen la no discriminación en el acceso a los servicios básicos como salud, empleo y educación, no hay una distinción entre las vivencias de discriminación para las personas trans y las cisgénero, y luego entre cada una de esas subdividiones.

Por lo anterior, es preciso especializar la construcción de los derechos humanos tomando en cuenta las diferencias socioculturales de cada letra L-G-B-T, atendiendo la identificación que las personas hacen de sí mismas al ser lesbianas, gays, bisexuales y personas trans, y cómo se identifican con su grupo, no desde la identidad que se les construye desde afuera, donde son los otros señalándoles a ellos y ellas, pues la identidad en tanto construcción histórica y política, se caracteriza por estar sometida a procesos de ficcionalización y, por lo tanto, ser incompleta, abierta y estar sujeta a la indeterminación de un sentido, o la indeterminación de una lucha política que nunca podría clausurarse (Sabsay 2011, 35).

De ahí que Argüello propone entender las identidades como dinámicas de estrategias de acción, oportunidades políticas y recursos organizativos y pasar de la noción de identidad al de identificaciones, como entidades que remiten 
a la constitución de grupos emergentes en relación con demandas políticas. "Las identificaciones refieren a las formas como los actores sociales asumen una posición de sujeto en las configuraciones sociales en las que interactúan" (Argüello 2013, 181). Es decir, cada persona configurada en un cuerpo define lo que es y establece demandas.

Las colectividades se forman entonces a partir de un proceso de identificación individual, se reconocen entre ellas y forman un "nosotros", lo que da una noción de grupalidad, sin perder nunca las diferencias en el interior. Esto les permite construir agendas, establecer relaciones ya sea de cooperación o de confrontación, así como ordenar y dar sentido al contexto. La identificación no desdibuja la heterogeneidad entre los miembros de la colectividad.

Resulta, por lo tanto, fundamental politizar las diferencias de estos cuerpos disidentes y hacerlas presentes en la esfera pública, para darles visibilidad, pero también para ofrecerles posibilidades de transformación. La discusión pública de las diferencias está ligada a una concepción del florecimiento humano vinculada con la participación, la deliberación conjunta de los implicados, el acuerdo, la comunicación, la negociación y el compromiso de las diferencias (Del Águila 2019).

En ese sentido, la construcción de los derechos humanos, la discusión de los modelos de ciudadanía y el diseño y elaboración de políticas públicas deben cumplir como requisito la participación de las personas LGBT para, desde sus experiencias y vivencias, puedan construirse derechos situados.

Desde esta premisa, sería interesante repensar los derechos humanos para las personas LGBT; de lo contrario, se seguirá diseñando derechos desde la lógica del sistema heteropatriarcal, binario y cisgénero. Todavía más, las políticas públicas que se elaboran son desde esta lógica, y esta concepción identitaria tiende a oscurecer las diferencias dentro de los grupos y pueden también exacerbar las tensiones entre ellos, ya que una lógica institucional dependiente de la reivindicación de identidades construidas como mutuamente excluyentes inevitablemente implica la competencia por recursos y acceso político (Pecheny \& de la Dehesa s.f.).

\section{Los derechos humanos sociosexuados}

La democracia sexual, entendida en términos de políticas de equidad de género y reconocimiento de la diversidad sexual y de género, aunque loable en sus ideales, no es ajena a la rearticulación de cierta jerarquía sociosexual, en la que junto al heterocentrismo imperante, se generen nuevas homonormatividades en las que la familia y la pa-

reja como modelos hegemónicos de organización social 
siguen siendo centrales. Las políticas de reconocimiento se promocionan como la realización de un progresivo avance de la libertad sexual, pero en realidad su dinámica es bastante más contradictoria (Sabsay 2011, 32).

Los derechos humanos no han escapado a esta estructuración sociosexual que se viven en las democracias que están garantizando derechos a sus ciudadanos/as; hay una inclinación significativa por disciplinar a los cuerpos no heteronormados hacia las prácticas hegemónicas de las personas heterosexuales; de ahí la centralidad por resguardar el matrimonio entre personas del mismo sexo y la adopción; ambas son prácticas que refuerzan la idea de familia. Cabe señalar que esta es el espacio íntimo por excelencia donde se asegura el éxito de la vida pública. Además de que la acotación hacia la enunciación de estos derechos centraliza las demandas de las personas cisgénero pertenecientes a la diversidad sexual, por lo que quedan fuera las personas trans y aquellas que deseen optar por otras formas de vida.

La importancia de un enfoque de identificación, como se señaló en párrafos anteriores, en el señalamiento de prácticas discriminatorias y derechos humanos para las personas LGBT, tiene como principal motivación matizar las legislaciones y políticas públicas que emprenden los Estados, pues es muy plausible que estos, nuevamente, desde un marco legal y de acción administrativa, promocionen la heterosexualización tanto en el espacio público como en el privado.

El reconocimiento legal de las uniones entre personas del mismo sexo consagra al modelo de familia heterosexual de clase media como el patrón a seguir, ya que los arreglos de convivencia alternativos no reciben igual protección. Este sesgo posee variados efectos tanto sobre la vida pública como sobre el espacio íntimo de los ciudadanos. Las reivindicaciones basadas en reclamos de derechos encuentran su límite cuando el reconocimiento parcial reproduce la desigualdad y refuerza la clasificación jerárquica de prácticas y sujetos (Moreno 2006, 123-124).

En este sentido, la vida privada, al no poder quedar ajena de la vida pública como lo enuncia la democracia liberal, se estructura, por medio de leyes y políticas que codifican valores dominantes. De este modo las relaciones familiares, eróticas y afectivas están marcadas como un espacio heterosexual en las sociedades occidentales y la consigna es tratar de que los cuerpos no heteronormados se constriñan a prácticas heterosexuales para hacerlos coincidir, por lo menos, en estilos de vida con los esquemas sexuales "normales", y desde ahí "aceptarlos", con un poco de mayor facilidad para suavizar lo anormal, y para no romper con la armonía y estética del paisaje social.

Así, el matrimonio entre personas del mismo sexo se representa mediante cuerpos de hombres homosexuales y mujeres lesbianas, todos atractivos, con un estatus económico medio o medio alto, que reproducen la idea de la familia con hijos. Y, entonces, se explota la imagen de artistitas comerciales 
que encajan perfectamente bien con estas representaciones que hace el mercado acerca de los cuerpos: estilizados, atractivos, blancos, de clase media o media alta y que consumen mucho y viven felices.

\section{Reflexiones finales}

Los derechos humanos resuelven, por estatus supranacional, algunas de las defiencias que en materia de violencia y discriminación se suscitan en los Estados-nación que han firmado acuerdos internacionales en esta materia. En este sentido, las organizaciones y colectivos defensores de las personas de la diversidad sexual y de género han recurrido a dichos derechos para dignificar sus vidas, denunciar atropellos y mejorar su condición ciudadana.

Los derechos humanos entran a subsanar la condición personal, humana, política, civil y social de las personas LGBT, una condición que los proyectos democráticos no han podido otorgar del todo. Esto debido a la estructura ontológica que guarda la democracia liberal y su modelo de ciudadanía normativa, donde lo diverso no tiene cabida, por amenazar la máxima de la igualdad (una igualdad abstracta ante la ley que no contempla las diferencias marcadas en otros ámbitos).

El modelo de ciudadanía que impera al interior de los Estados democráticos es un paradigma excluyente que propicia violencias y discriminación de todas aquellas personas que no cumplen con la condición estándar de ciudadano/a, por lo que los derechos humanos, en su condición de valor supranacional, subsanan lo que el marco legal democrático de los Estados no contempla, invisibiliza o simplemente no está construido para atender.

Los derechos humanos se han convertido en una zona discursiva de refugio para muchos grupos violentados; pero para hacerlos valer se requieren competencias sofisticadas que no todas las personas tienen y pueden ejercer. Los derechos humanos son un recurso aún privilegiado y al recurrir a ellos de forma extraordinaria no modifica de raíz la estructura heteropatriarcal, cisgénero y binaria que violenta y discrimina la diversidad sexual y de género.

Traducir los acuerdos y tratados que firman los Estados-nación (en materia de derechos humanos en beneficio de las personas LGBT) en políticas públicas es todavía muy complicado, puesto que muchas de las recomendaciones que hacen las diferentes instancias como la Corte Interamericana de Derechos Humanos (CIDH), son resueltas parcialmente por las naciones en términos administrativos muy suaves o de modo extraordinario, sin bajarlas al terreno operativo cotidiano de las políticas públicas.

Las políticas públicas son un mecanismo de distribución de bienes y prerrogativas. Son, además. instituciones que -se sabe de antemano- están diseñadas para incluir o excluir a determinados tipos de personas dentro de la comunidad política que alberga todo un sistema de creencias e intereses muy concretos. Las políticas públicas definen la ciudadanía y sus contenidos, van 
a delimitar los cuerpos que importan, los que no importan y los que tienen el carácter de vulnerables.

En este tenor, toda política pública propicia la transformación o reproducción del orden social y político, la forma como serán resueltos los conflictos, así como la integración de los grupos sociales (Pecheny y Dehesa 2009,1). Cuando las políticas públicas resuelven un problema, lo hacen con base en dos sentidos: práctico y simbólico, lo que revela el posicionamiento del Estado y la sociedad frente a las problemáticas. La ausencia de políticas es también un posicionamiento político.

En este sentido, ni el Estado, como entidad política de poder ni la sociedad, ha logrado modificar su concepción acerca de la diversidad sexual y de género. El orden heterosexual, cisgénero y binario es el eje articulador de la vida pública y privada a partir del cual se ordenan los cuerpos.

No es hasta hoy que las políticas públicas generadas, empiezan a atender parcialmente a la población LGBT y lo hacen desde una lógica sociosexuada; es decir, reproducen estilos de bienestar anclados en los prototipos de vida heterosexual: matrimonio igualitario y adopción. Su finalidad es aproximarlos a lo "aceptable", lo "normal", de conformidad con una estética social validada y reconocida.

Las personas LGBT tienen que ser actores y actrices clave del reconocimiento de derechos y de la política pública que de ellos se derive. En la medida en que estas personas sean incoporadas en las discusiones se corre menos riesgo de tener sesgos heteronormativos y cisgénero de las prerrogativas reconocidas y las políticas públicas generadas.

Los derechos humanos poco han podido escapar de este orden sociosexuado y de la clara diferenciación entre las personas de la diversidad sexual y de género. Es necesario construir los derechos humanos de las personas LGBT desde la perspectiva de género, la diferenciación y rompiendo el paradigma de la identidad para entender estas poblaciones desde su identificación, donde además lo trans no quede subsumido a lo cisgénero.

Entender las discriminaciones y violencias desde estas diferenciaciones hacia dentro del grupo implica construir derechos humanos más apegados a las necesidades sociocultuarles de cada una de las identidades L-G-B-T. Lo anterior como primer paso, para posteriormente trabajar en conjunto con las personas LGBT; aquí son muy importantes los colectivos y las organizaciones para que todos los derechos humanos que se reconozcan tengan su anclaje en lo situado. Particularmente, en el reconocimiento de derechos de las personas trans deben existir representantes de esta identidad para que estos sean potentes y en verdad atiendan sus necesidades desde sus propias vivencias.

Los derechos humanos han resultado ser dispositivos muy potentes, sin embargo, su margen de acción dentro de los Estados-nación es muy acotada porque solamente pueden formular recomendaciones desde una obligatoriedad suave, que incide poco en la vida diaria de las personas, al tiempo que 
los Estados omiten legislar seriamente en ese sentido y erradicar las exclusiones de esta población desde el núcleo central que le da orden a su paradigma cívico-público.

\section{Referencias}

Argüello Pazmiño, Sofía. 2013. «El proceso de politización de la ciudadanía: identificaciones y marcos de sentido de la acción colectiva». Revista Mexicana de Sociología, 7(2): 173-200. Acceso el 30 de mayo de 2017. Disponible en http://mexicanadesociologia.unam.mx/docs/vol75/num2/v75n2a1.pdf.

Centro de Estudios Internacionales Gilberto Bosques. 2016. Documento de Investigación. Los derechos de las personas LGBTI en el mundo y la Situación en México. México: Senado de la República.

Comisión Internacional de Juristas. 2009. Orientación Sexual, e Identidad de Género y Derecho Internacional de los Derechos Humanos. Ginebra: Comisión Internacional de Juristas.

Comisión Nacional de Derechos Humanos México. 2017. Los Derechos Humanos de las Personas Transgénero, Transexuales y Travestis, Ciudad de México: Comisión Nacional de Derechos Humanos.

Consejo para Prevenir y Eliminar la Discriminación de la Ciudad de México. 2017. «Población LGBTTTI». En Monografías por la No Discriminación. Ciudad de México: COPRED. Acceso el 14 de agosto de 2017. Disponible en http://data.copred.cdmx.gob.mx/por-la-nodiscriminacion/poblacion-lgbttti/

Del Águila, Rafael. (1999). «La tolerancia». Teoría Política: poder, moral, democracia, editado por Aurelio Arteta; Elena García Guitián y Ramón Máiz, 362-383. Madrid: Editorial Alianza.

Estefan Vargas, Soraya. 2013. «Discriminación estatal de la población LGBT. Casos de transgresiones a los Derechos Humanos en América Latina» Revista Sociedad y Economía, 25 (1): 183-204. Acceso el 12 de junio 
de

2017.

Disponible

en

http://www.scielo.org.co/pdf/soec/n25/n25a09.pdf.

Garrido Álvarez, Rafael José. 2017. «La despenalización de la homosexualidad en Ecuador: el legado de la acción colectiva LGBTI». Creative Commons. Trabajo almacenado en el Repositorio Institucional UaSB-DIGITAL con licencia Creative Commons 3.0 Ecuador: 52. Acceso el 30 de noviembre de 2017. Disponible en http://repositorio.uasb.edu.ec/bitstream/10644/5776/1/PI-2017-04-

Garrido-La\%20despenalizaci\%C3\%B3n.pdf?

fbclid=IwAROSUaAtr5qt8J_zFmXbqFumNI-

OTtEXQc4XUdt3SdHK Ip9A_ZDq54q|4

Lind, Amy and Sofía Argüello Pazmiño. 2009. «Ciudadanías y sexualidades en América Latina». Íconos 35 (1): 13-18. Acceso el 12 de mayo de 2017.

Disponible

en

http://repositorio.flacsoandes.edu.ec/bitstream/10469/905/4/RFLACSOI35-01-Lind.pdf.

Naciones Unidas. 2013. Orientación Sexual e Identidad de Género en el Derecho Internacional de los Derechos Humanos. América del Sur, Oficina Regional de la Oficina del Alto Comisionado, Derechos Humanos.

Moreno, Aluminé. 2006. «Ciudadanía y sexualidad en la ciudad de Buenos Aires"» Nómadas, 24 (1): 118-128. Acceso el 20 de marzo de 2017 http://www.redalyc.org/articulo.oa?id=105116598011

Pecheny, Mario and Rafael de la Dehesa. S.f. «Sexualidades y Políticas en América Latina: un esbozo para la discusión». Río de Janerio: Sexuality Policy Watch. Acceso del 03 de marzo de 2017 http://www.sxpolitics.org/pt/wp-content/uploads/2009/10/sexualidades-ypoliticas-en-america-latina-rafael-de-la-dehesa-y-mario-pecheny.pdf 
Peña Echeverría, Javier. 2010. «La ciudadanía». Teoría Política: poder, moral, democracia, editado por Aurelio Arteta; Elena García Guitián y Ramón Máiz, 215-245. Madrid: Editorial Alianza.

Plummer, Ken. 2001. «The Square of Intimate Citizenship: some Preliminary Proposals». Citizenship Studies 5 (1): 237-253. DOI:10.1080/13621020120085225

Plummer, Ken. 2003. Intimate Citizenship: Private Decisions and Public Dialogues. Seattle: University of Washintong Press.

Preciado, Beatriz. 2011. Manifiesto contrasexual. Barcelona: Editorial Anagrama.

Rabotnikof Maskivker, Nora, 2005. «Ciudadanía y Derechos». Derechos de Ciudadanía. Responsabilidad del Estado editado por Manuel Canto, 2948. Barcelona: Icaria Política.

Richardson, Diane. 2000. Rethinking Sexuality. London: Sage Publications.

Sabsay, Leticia. 2011. Fronteras sexuales. Espacio urbano, cuerpos y ciudadanía, Argentina: Paidós.

Young, Iris Marion. 1998. «Imparcialidad y lo cívico-público. Algunas implicaciones de las críticas feministas a la teoría moral y política». La democracia en sus textos editado por Rafael Del Águila; Fernando Vallespín; et. al, 445-469, Madrid, Alianza Editorial. 